\title{
EL CANTAR DE LOS CANTARES Y LA ESCRITURA MEDIEVAL: RICHARD ROLLE DE HAMPOLE (CA. 1300-1349)
}

\author{
María Eugenia Góngora \\ Universidad de Chile, Santiago de Chile, Chile \\ egongora@u.uchile.cl
}

\section{RESUMEN / ABSTRACT}

En la primera parte de este ensayo se relevan algunas características de las tradiciones de lectura y de reescritura del Cantar de los Cantares durante la Edad Media. A partir de estas tradiciones, se explora la reelaboración que de ese texto bíblico realizó el místico inglés Richard Rolle (ca.1300-1349). Estas consideraciones nos llevan a concluir que el Cantar fue uno de los textos fundamentales en la exploración de la subjetividad y del amor entre sus lectores medievales, haciendo confluir de este modo las tradiciones interpretativas de rabinos y de lectores y exégetas cristianos.

Palabras clave: Cantar de los Cantares, exégesis, amor místico, subjetividad, Richard Rolle.

THe SONG OF SONGS AND MEDIEVAL WRITING: Richard Rolle OF Hampole (c. 1300-1349)

In this essay, I first explore some of the main characteristics of the medieval reading and writing traditions of the biblical Song of Songs. The rewriting of the Song of Songs in the mystical texts of Richard Rolle (c. 1300-1349) leads us to conclude that the Song was one of the most important texts in the exploration of subjectivity and love of his medieval readers, thus joining the hermeneutical traditions of both Jewish and Christian readers and exegetes.

KEYWORDS: Song of Songs, exegesis, mystical love, subjectivity, Richard Rolle.

Recepción: 22/09/2018

Aprobación: 23/11/2018 
"Ungüento derramado es tu nombre”

Cantar 1:3

"Abrí a mi amado, pero mi amado se habia ido. El alma se me salió a su huida. Le busqué y no le hallé, le llamé, y no me respondió. 7 Me encontraron los centinelas, los que hacen la ronda en la ciudad. Me golpearon, me hirieron, me arrancaron mi manto los guardias de las murallas. 8 Yo os conjuro, hijas de Jerusalén, si encontráis a mi amado, ¿qué le habéis de anunciar? Que languidezco de amor”.

Cantar $5: 6-8^{1}$

En este ensayo se relevan algunas de las características de la lectura y de la reescritura del Cantar de los Cantares durante la Edad Media y se explora la reelaboración que de ese texto bíblico realizó el místico inglés Richard Rolle (ca.1300-1349).

Este trabajo tuvo su origen en una investigación sobre los principales hitos textuales en la historia de una devoción que está centrada en una imagen poderosa -la del corazón inscrito-y en particular, en la historia de la devoción del nombre de Jesús inscrito en el corazón de los creyentes ${ }^{2}$. En ese contexto, el libro del Cantar de los Cantares y, en particular, el versículo del Cantar 1:3, "ungüento derramado es tu nombre", y sus lecturas medievales, derivó en otra búsqueda, la de las reelaboraciones medievales del Cantar, uno de los textos bíblicos más frecuentemente citados, glosados y comentados en una prolongada tradición teológica, doctrinal, litúrgica y literaria y que se extiende, como sabemos, mucho más allá del siglo XV.

El Cantar, que pertenece al grupo de libros sapienciales del Antiguo Testamento, sobre cuyo origen, datación y posibles interpretaciones han

\footnotetext{
Para las citas del Cantar prefiero utilizar la Biblia de Reina Valera (1960) por razones de estilo, y las cotejo siempre con la versión de Biblia de Jerusalén (1975), dado su reconocido valor filológico. En cuanto a la última frase del versículo 5: 6-8, ("porque estoy enferma de amor"), sustituyo esta versión por la traducción de la Vulgata, "quia amore langueo". Utilizo la edición bilingüe de la Vulgata de A. Colunga y L. Turrado. Se puede cotejar también la Nova Vulgata del portal del Vaticano www.vatican.va/archive/bible/nova_vulgata/documents/ nova-vulgata_vt_canticum-canticorum_lt.html

2 A este respecto me permito referir a mi estudio "El Corazón Inscrito". Revista Chilena de Literatura 73 (2008): 217-223.
} 
existido numerosos estudios ${ }^{3}$, es un texto en el que paradójicamente -al menos en apariencia- no se menciona el nombre de Dios; y fue justamente ese libro el que, se nos dice, fue considerado por los rabinos el libro más sagrado entre los que fueron entregados por Dios al pueblo de Israel. Y para Bernardo de Claraval (1090-1153), en su Sermón I, "solo la unción [del Espíritu] pudo inspirar un cantar como éste, y solo la experiencia puede desentrañar su sentido" $(86)^{4}$.

Las interpretaciones alegóricas fueron, desde un comienzo, una guía para los lectores de este conjunto de cantos, que asumen la forma de un diálogo entre dos amantes, el Esposo y la Esposa, y es muy probable que su presencia en el canon haya sido posible gracias a la interpretación espiritual del Cantar, que se ha dado tanto en el ámbito de la exégesis judía como en la cristiana. De acuerdo a esta tradición, la figura de los esposos y la expresión de su relación amorosa funcionarían esencialmente como signo de la unión entre Iahveh y su pueblo, entre Dios y su Iglesia, entre Dios y María (Madre y Esposa a la vez), entre Dios y el alma individual. Por otra parte, la interpretación de las amigas y los amigos de los esposos que aparecen también en el Cantar ha propuesto una analogía de esos personajes con las figuras de la Iglesia y de la comunidad cristiana. Aparecerán también más tarde aquellas lecturas que ven en el Cantar una colección de cantos amorosos insertos básicamente en la tradición musical y ritual del Oriente Medio y el Egipto.

En la tradición cristiana, ya en Orígenes (ca. 185-253) en su Comentario y en sus Homilías, el Cantar aparece como una guía y fundamento para

3 Algunos estudios de conjunto sobre el Cantar y sus interpretaciones se encuentran en Perspectives on the Song of Songs/ Perspektiven der Hoheliedauslegung. Ed. Anselm C. Hagedorm. Berlin \&New York: De Gruyter, 2005; Turner, Denys. Eros and Allegory: Medieval Exegesis of the Song of Songs. Michigan: Kalamazoo, 1995; Roland Murphy, O Carm. The Song of Songs: a Commentary on the Book of Canticles, or the Song of Songs. Minneapolis: Augsburg Fortress, 1990, así como también los estudios de Ann Astell y Ann Matter referidos en la bibliografía. Para un estudio específico sobre el Cantar en la obra de Teresa de Ávila, ver Lawrence S. Cunningham. "Teresa of Avila on the Song of Songs". The Renewal of Mystical Theology, Essays in Memory of John N. Jones (1964-2012). Ed. Bernard McGinn. New York: Herder \& Herder Book, The Crossroad Publishing Company, 2017.131-139. Una obra a la que no he podido tener acceso es el importante estudio de Friedrich Ohly. Hohelied-Studien,: Grundzüge einer Geschichte der Hoheliedauslegung des Abendlandes bis zum 1200. Wiesbaden, 1957. Ohly fue también el autor de la edición crítica de un importante comentario al Cantar del siglo XII, conocido como el St.Trudperter Hohelied. Berlin: De Gruyter, 1995.

En el original, "Istusmodi canticum sola unctio docet, sola addiscit experientia", San Bernardo. Sermón I, VI-11 (86). 
emprender un camino de unión con Dios (Orígenes 22-23) ${ }^{5}$. Para emprender este camino y para obtener buenos frutos del acercamiento al Cantar hay que estar preparado, ser capaz de superar también las primeras lecturas que despiertan los sentidos exteriores y que nos podrían desviar del "verdadero sentido" amoroso y religioso que se quiere enseñar; como bien sabemos, la justificación de la presencia de un texto en el canon bíblico fue desde un principio su posibilidad de ser enseñado y esta intención doctrinal se cumpliría ampliamente en las obras de Orígenes, San Bernardo y otros exégetas medievales.

Ya sea que la Esposa del Cantar fuera comprendida como el pueblo de Israel o que fuera interpretada más tarde como la Iglesia, o como María, o bien como el alma individual, (sobre todo a partir de los siglos XI y XII), lo cierto es que este texto se convirtió durante los siglos medievales en una fuente inagotable de enseñanzas, citas, glosas y de numerosas referencias intertextuales, tanto en latín como en las lenguas vernáculas, entre las que consideraremos los denominados Escritos Ingleses de Richard Rolle ${ }^{7}$. Y es interesante constatar la importancia de la exégesis del Cantar en el mundo monástico, un ámbito en el que quizás no esperaríamos un interés tan marcado

5 La traducción latina de Orígenes en la traducción de San Jerónimo. Origenis In Canticum Canticorum, se puede consultar en la Patrologia Latina 23, CIII7-44. Existe también una edición castellana: Orígenes. Comentario al Cantar de los Cantares. Trad. A. Velasco Delgado O. P. Introducción y notas de Manlio Simonetti. Madrid: Ciudad Nueva, 2007 (1986).

En su importante estudio sobre los llamados "Rothschild Canticles", un libro de horas compuesto posiblemente a comienzos del siglo XIV, Jeffrey Hamburger explica el programa iconográfico de una de las secciones de ese libro, muy probablemente dedicado al uso de una mujer religiosa, y alude a la interpretación del texto y de las imágenes dedicadas a la exégesis y al comentario del Cantar de los Cantares. En esta exégesis, el es Cristo y el alma (femenina e individual) es la Esposa. Jeffrey Hamburger. The Rothschild Canticles, Art and Mysticism in Flanders and the Rhineland circa 1300. New Haven and London: Yale University Press, 1990. En el capítulo 5 de esa obra, dedicado a las miniaturas del Cantar, así como en el capítulo 7, dedicado a las miniaturas relacionadas con la unión mística, Hamburger enfatiza la importancia del Cantar y de la figura de la Esposa en la así llamada mística esponsal durante los siglos tardíos de la Edad Media (70-87 y 105-117).

Para un resumen de la reescritura del Cantar en lenguas vernáculas, tanto en comentarios como el St. Trudperter Hohelied (h. 1160), dedicado a una comunidad de mujeres religiosas, como en variados escritos devocionales y líricos, ver "The Genre as Trope: The Song of Songs in Vernacular Literature" (Matter 178-179). Ver también en Ann W. Astell los capítulos "Middle English Transitions: The Case of Richard Rolle" y "Religious Love Lyric and the Feminine I" (105-118 y 136-158, respectivamente). 
por un texto de estas características. Gracias en buena medida a los estudios del dominico Jean Leclercq sobre el amor en el mundo monástico medieval ${ }^{8}$, podemos comprender mejor la importancia y las funciones de la enseñanza y la lectura del Cantar para las órdenes religiosas.

Es relevante recordar aquí también, como lo hace Duncan Robertson en su Lectio Divina, el camino recorrido a partir de la exégesis de Orígenes, si tenemos en cuenta la importancia de la Exposición de Gregorio el Grande (ca. 540-604) en su Comentario al Cantar (Robertson 170-172). Afirma San Gregorio que desde que el alma fue expulsada del paraíso por el pecado, peregrina ahora por la tierra sin capacidad de visión espiritual, sin sensibilidad para comprender el llamado de Dios. "Es por esa razón que en el libro del Cantar de los Cantares se habla del amor físico; para que así el alma sea tocada [frotada] y se tempere, saliendo de su letargo gracias a que escucha expresiones que le son familiares, y que sea exaltada desde el amor más bajo al amor más elevado. Por esa razón se nombran aquí los besos, así como los pechos, las mejillas y los muslos. El discurso sagrado no se trivializa [la descripción sagrada no se hace digna de burla] por el uso de esas palabras, y es en verdad la misericordia de Dios la que contemplamos" (Robertson 172).

Ya durante los siglos medievales, y tal como lo señalan tanto Leclercq como Robertson, las órdenes emergentes en el siglo XII, las de los victorinos, los premonstrateneses y los cistercienses, reclutaron a sus miembros entre grupos de adultos que, en muchos casos, tenían experiencia de la vida secular y de la literatura cortesana y amorosa; para ellos, el Cantar de los Cantares tendría una especial resonancia. Cuando San Bernardo explicaba a sus monjes el Cantar y los invitaba literalmente a "abrir sus mandíbulas" para comer el texto como si éste fuera un pan espléndido y sabroso, que hay que partir y compartir (Sermones 98-99) ${ }^{10}$, cada verso se podía convertir en una guía, un

$8 \quad$ Leclercq, Jean. L'Amour vu par les moines au XIIe siècle. Paris: Editions du Cerf, 2007. 21-25. La edición original en inglés es la ya mencionada bajo el título de Monks and Love in XIIth Century France. Oxford: Oxford University Press, 1979.

9 En el texto latino original "Nominantur enim in hoc libro oscula, nominantur ubera, nominantur genae, nominantur femora; in quibus verbis non irridenda est sacra descriptio, sed maior dei misericordia consideranda est. . ." (Robertson 171). La traducción de la versión inglesa de D. Robertson es mía y la frase entre paréntesis cuadrado es mi versión del texto latino.

10 En el original latino "Itaque parate fauces non lacti, sed pani... Est panis apud Salomonem ... proferatur, si placet, et frangatur" (Robertson 180-181). 
camino y una cantera de tesoros a la cual se vuelve una y otra vez, siguiendo a veces el camino de la explicación literal, a veces la alegórica y la moral, pero siempre volviendo a su literalidad, asegurando así su apropiación y su pertinencia cultural.

El Cantar enseñado por los monjes y para los monjes, se convirtió así en "el libro de la experiencia"11, un libro personal para cada lector, en la medida en que el diálogo amoroso se pudo asumir desde la voz de la protagonista, la voz de la mujer "negra pero hermosa" (4) que busca, espera y acoge a su amado. Como lo ha planteado Jean Leclercq, la búsqueda del amado, asumida como un camino de contemplación, debió ser uno los aspectos fundamentales de la lectura del Cantar en la experiencia los monjes medievales (Leclercq 84-86).

La afectividad característica de esa enseñanza del Cantar, y su énfasis en la experiencia, nos permite proyectar una reflexión sobre los orígenes medievales de las subjetividades modernas, y que debería tener en cuenta la alteridad (y la cercanía tal vez inesperada) de la experiencia mística en distintos contextos históricos y culturales ${ }^{12}$. En el ámbito medieval, específicamente, el "yo" de los autores místicos puede ser entendido esencialmente como un diálogo nupcial con Dios, tal como se experimentaría en la contemplación del Cantar de los Cantares. Por otra parte, el "yo" surge también a partir de una consideración del libro del Génesis: hombres y mujeres son una Imago Christi, una imagen de Cristo que está asociada a las palabras “A su imagen y

11 En el original latino "Hodie legimus in libro experientiae. Convertimini ad vos ipsos, et attendat unusquisuqe conscientiam suam super his quae dicenda sunt" y en la traducción castellana "Hoy abrimos el libro de la experiencia. Volveos a vosotros mismos y que cada cual escuche en su interior lo que vamos a decir" (San Bernardo 98-99).

12 Existe una muy abundante bibliografía para la consideración de las subjetividades medievales. Citaré aquí a Caroline Walker Bynum. Jesus as Mother. Studies in the Spirituality of the High Middle Ages. Berkeley \& Los Angeles: University of California Press, 1984; Michel Zink. La Subjectivité littéraire autour du Siècle de Saint Louis. Paris: P.U.F., 1985; Sarah Kay. Subjectivity in Troubadour Poetry. Cambridge: Cambridge University Press, 1990; Sarah Spence. Texts and the Self in the Twelfth Century. Cambridge: Cambridge University Press, 1996; C. Stephen Jaeger. Ennobling Love. In Search of a Lost Sensibility. Philadelphia: The University of Pennsylvania Press, 1999; Le Sujet des Émotions au Moyen Âge. E. Piroska Nagy y Damien Bosquet.Paris: Beauchesne, 2008; A. C. Spearing. Medieval Autographies. The "I" of the Text. Notre Dame: University of Notre Dame Press, 2012. Para un período posterior, ver Michel de Certeau. La Fable Mystique I Paris: Gallimard, 1982 y La Fable Mystique II. Paris: Gallimard, 2013. 
semejanza los creó" (Génesis 1, 26-27) ${ }^{13}$. En este sentido se ha podido pensar que la centralidad de la Imago hacia el siglo XII se fundó en un renovado interés por la creación: la creación del hombre como imagen de Dios, y la creación de Cristo como imagen de Dios sobre la tierra, si pensamos en términos de la teología de la Encarnación ${ }^{14}$.

Por otra parte, como la voz inicial en el texto del Cantar es femenina, serán los propios exégetas los que irán llevando a sus auditores y lectores a una progresiva identificación con la Esposa (Robertson 193); en este sentido es posible hablar de una feminización de la voz mística: frente al otro, frente al Esposo, el Yo se expresa y se representa a sí mismo como mujer ${ }^{15}$. En definitiva, podemos pensar que en una exégesis tan influyente como lo fue la de San Bernardo en el ámbito monástico, la afectividad y la cercanía de las imágenes amorosas con la experiencia, permitieron que esas imágenes

13 Génesis 1:26: "Y dijo Dios: Hagamos al ser humano a nuestra imagen, como semejanza nuestra, y manden en los peces del mar y en las aves de los cielos y en las bestias y en todas las alimañas terrestres, y en todas las sierpes que serpean por la tierra". 1: 27: "Creó, pues, Dios al ser humano a imagen suya, a imagen de Dios le creó, macho y hembra los creó". Ver también San Agustín. De Trinitate, XII, 6-8; Obras de San Agustín, Tratado sobre la Santísima Trinidad. Tomo V. Ed. Luis Arias, O. S. A. Madrid: B.A.C., 1948. 661-673.

14 En un importante estudio sobre el pensamiento de los pre-escolásticos del norte de Europa en el siglo XII, Brigitte Miriam Bedos-Rezak propone una distinción entre la imagen que proviene del reflejo (el espejo o el agua), por una parte, y la imagen que proviene del sello, (el sigillum) y de su impronta en la cera. Para esta autora, la identidad material entre el sello y la imagen impresa en la cera sería, al menos en el siglo XII y antes de la masificación de esta técnica, la metáfora más apropiada para pensar la relación entre el hombre como imagen de Dios, en términos de filiación, derivación y contacto. Bedos-Rezak. Miriam. "Replica: Images of Identity and the Identity of Images in Prescholastic France". The Mind's Eye. Art and Theological Argument in the Middle Ages. Ed. Jeffrey Hamburger and Anne-Marie Bouché. Princeton N.J.: Princeton University Press, 2006.46-64. Sobre la Imago dei y la lectura del Libro del Génesis, ver también Jeffrey Hamburger. Saint John the Divine: The Deified Evangelist in Medieval Art and Theology. Berkeley \& Los Angeles: University of California Press, 2002. 2-3; y los capítulos 7 y 8 sobre la imago dei y la teología de la deificación, 179183 y 185-201, respectivamente. Ver también Jean-Claude Schmitt. "La culture de l'imago" en Annales 51-1. 1996, 3-36, y su libro Le corps des images. Essais sur la culture visuelle au Moyen Âge. Paris: Gallimard 2002. Para una revisión de las teorías medievales sobre la imagen desde la perspectiva de la historia de la Filosofía, ver Olivier Boulnois. Au délà de l'Image. Une archélogie du visuel au Moyen Age, du VIème au XVIème siècle. Paris: Seuil, 2008.

Para la identificación con la Esposa frente al Amado divino en el Islam, ver Annemarie Schimmel. My Soul is a Woman. The Feminine in Islam. New York \& London: Continuum 2003. En especial el capítulo 8, “The Brides of God” (107-117). 
funcionaran como 'señales' que debían conducir al encuentro de la Esposa - del alma individual- con el Esposo, así como a la contemplación que solo se realizará con plenitud en otra vida ${ }^{16}$.

Hemos afirmado aquí que en el mundo monástico la afectividad de las interpretaciones y la imaginería amorosa no está limitada a los comentarios sobre el Cantar; las referencias a éste están también presentes en la liturgia ${ }^{17}$, en la poesía lírica religiosa y en las representaciones dramáticas de los relatos bíblicos ${ }^{18}$. Por eso, desde el punto de vista de la historia literaria, y teniendo en cuenta que en los mismos siglos de la historia europea existió una importante tradición de poesía y narrativa cortesana centrada en "la aventura y el amor", de acuerdo a las palabras de Reto Bezzola, y que fue también conocida en el ámbito monástico -y entre las mujeres letradas en general-, se puede afirmar que sin la exégesis y la reescritura del Cantar de los Cantares, la imaginería de la literatura medieval -religiosa y profana-se habría visto notablemente empobrecida.

Quizás no está de más citar en este punto cuáles son aquellas palabras del Cantar a las que con mayor frecuencia volvieron una y otra vez los comentaristas cristianos: Orígenes, Gregorio de Nysa, Gregorio el Grande, Beda el Venerable, Bruno de Segni, Guillermo de Saint-Thierry, Honorio de Autun, Rupert de Deutz, Alain de Lille y San Bernardo, para mencionar solo a algunos de los comentaristas influyentes en la primera Edad Media ${ }^{19}$.

16 Ver el Sermón 52, que desarrolla el sentido literal del versículo "Os conjuro, Hijas de Jerusalén. . . que no despertéis a la amada hasta que ella quiera”, Cantar 8:4. En el Sermón 52.2 leemos: "No dudo que en el cielo se realiza así exactamente, como lo leo en la tierra. El alma vivirá en toda su realidad lo que se describe en este pasaje" (San Bernardo 669).

17 Jean-Claude Schmitt menciona un ejemplo de ejecución musical del versículo "Osculetur me osculo de oris sui" (Cantar 1:1) en una ceremonia litúrgica celebrada en Ravenna y también la presencia del diálogo de los Esposos del Cantar en los ciclos dramáticos. "Par-délà le texte et l'image. Le Paradigme céleste de la Procéssion". René Wetzel y Fabrice Flückigel. Au-délà de l'illustration. Texte et image au Moyen Âge, Approches méthodologiques et pratiques. Zürich: Cronos Verlag, 2009. 45-60.

18 En su ya mencionado The Song of Songs in the Middle Ages, Ann W. Astell se refiere a los ciclos de Misterios ingleses, particularmente a los Misterios de York, en su relación con el carácter 'dramático' del Cantar, en cuanto éste es un texto eminentemente dialógico (159176). Ya Orígenes en su Prólogo al Cantar, afirma que este texto fue compuesto "in modum dramatis" (cit. en Astell 160).

19 Para una consideración detallada de varios de estos autores en relación con las interpretaciones de la Esposa como Ecclesia y María, ver "The Exemplary Bride: Ecclesia and Mary" (Astell 42-72). 
1 Cantar de los cantares de Salomón.

1:1 ¡Que él me bese con los besos de su boca! Porque mejores son tus pechos ${ }^{20}$ que el vino.

1:2 A más del olor de tus suaves ungüentos,

Tu nombre es como ungüento derramado;

Por eso las doncellas te aman.

1:3 Atráeme; en pos de ti correremos.

El rey me ha metido en sus cámaras;

Nos gozaremos y alegraremos en ti;

Nos acordaremos de tus amores más que del vino;

Con razón te aman.

1:4 Negra soy, hijas de Jerusalén, pero hermosa

Como las tiendas de Qedar,

Como los pabellones de Salmá.

1:5 No reparéis en que soy morena,

Porque el sol me miró. (Biblia Reina Valera 947)

El Cantar es, esencialmente y como sabemos, un diálogo entre una esposa y su esposo; la Esposa expresa su amor y su deseo con el versículo inicial, "¡Que él me bese con los besos de su boca!”, uno de los versículos más comentados y reelaborados por los exégetas; más adelante, y como está citado en nuestro segundo epígrafe, la Esposa da voz también a su lamento por el alejamiento del esposo y su búsqueda en la noche por las calles de la ciudad, expresando su dolor por las heridas que recibe; así envía un mensaje a través de las Hijas de Jerusalén, "qué le habéis de anunciar: que languidezco de amor"21.

$20 \quad$ Hay versiones modernas en las que se prefiere la expresión "amores" en vez de "pechos" o "mamas"; ya sea para traducir "quia meliora sunt ubera tua" de la versión de la Vulgata (Cantar 1:2), "memores uberum tuorum super vinum" (Cantar 1:4); también se he preferido la expresión "amores" para traducir las palabras del Esposo en Cantar 4:10: "Quam pulchrae suntmammae tuae, soror mea sponsa".

$21 \quad$ El versículo "quia amore langueo" (Cantar 5:8) fue interpretado y reelaborado múltiples veces por autores cristianos medievales, tanto poetas como músicos; esa tradición siguió vigente en compositores hasta por lo menos el siglo XVII. Uno de los más conocidos poemas medievales que reescriben el Cantar, es The Valley of Restless Mind. Este poema, probablemente escrito durante el siglo XIV, se encuentra en los manuscritos de Londres (Lambeth Palace Library Ms 853m, 7-14, y de Cambridge, Cambridge University Library Hh.4.12, fols, 41b-44a). Ambos manuscritos son del siglo XV. Al final de cada una de sus estrofas, se reiteran las palabras de la Esposa del Cantar "Quia amore langueo". Es interesante hacer notar que en este poema encontramos algunos cruces genéricos que son evidentes: así, las heridas recibidas por la esposa en el texto original del Cantar, son asociadas aquí a las 
Leemos también en el Cantar los versos del encuentro, en los que cada uno de los esposos canta la belleza del otro y el mutuo encantamiento amoroso. Las palabras que aluden a la belleza y a las cualidades de la esposa así como a la mutua posesión de los amantes pueden leerse, por ejemplo, en estos versículos:

4:12 Huerto eres cerrado, hermana mía, huerto cerrado, fuente sellada

4:13 Tus brotes un paraíso de granados

Con frutos dulces.

4:14 Nardo y azafrán, caña aromática y canela,

Con todos los árboles de incienso, mirra y áloe (Biblia Reina Valera 947)

6:3 Yo soy de mi amado, y mi amado es mío;

El apacienta entre los lirios. (Biblia Reina Valera, 949)

O también:

6:10 ¿Quién es ésta que se muestra como el alba,

Bella como la luna,

Refulgente como el sol,

Imponente como un ejército formado en batallones? (Biblia Reina Valera 949)

El diálogo y el cantar culminarán con la visión de la Esposa que sube desde el desierto y con los versos en los que se manifiesta la potencia del amor más fuerte que la muerte:-

8:5 ¿Quién es ésta que sube del desierto,

Recostada sobre su amado?

Debajo de un manzano te desperté;

Allí tuvo tu madre dolores,

Allí tuvo dolores la que te dio a luz.

8:6 Ponme como un sello sobre tu corazón, como una marca sobre tu brazo;

Porque fuerte es como la muerte el amor;

Duros como el Seol los celos;

Sus brasas, brasas de fuego, fuerte llama.

8:7 Las muchas aguas no podrán apagar el amor,

Ni lo ahogarán los ríos. (Biblia Reina Valera 950)

heridas de Cristo en su pasión; él es quien pronuncia estas palabras, invirtiéndose así los roles del Esposo y la Esposa. 


\section{“PORQUE LANGUIDEZCO DE AMOR”: RICHARD ROLLE}

Richard Rolle, llamado 'El ermitaño de Hampole' (ca. 1300-1349), vivió en la región de Yorkshire, donde su culto floreció a lo largo de varios siglos, a pesar de que nunca fue canonizado. Tuvo que abandonar sus estudios en Oxford por razones que no son conocidas, y sus numerosas obras, escritas tanto en latín como en inglés, forman parte de la renovada tradición de la escritura de los anacoretas y del desenvolvimiento de la devoción marcada por la afectividad que conocemos a partir del siglo XII, especialmente en relación con la escritura de los cistercienses y de San Bernardo (Minnis 70) ${ }^{22}$. En este contexto se pueden comprender sus escritos, de los cuales se conocen una veintena de composiciones: tratados exegéticos, cartas, poemas y textos autobiográficos. Rolle fue uno de los autores místicos más leídos e influyentes en la Inglaterra medieval, así como también en el Continente, y sus obras se han conservado en más de quinientos manuscritos (McGinn 339$)^{23}$.

Desde su reclusión, Richard Rolle sostuvo una relación pastoral con mujeres religiosas de su entorno y, en particular, con la reclusa Margaret Kirkeby. A ella dedicó uno de sus 'escritos ingleses', The Form of Living, en el cual encontramos una expresión muy clara de su devoción a Jesús y a su nombre ${ }^{24}$, y desarrolla asimismo una reflexión muy compleja sobre el amor, como en el resto de sus obras.

A partir del capítulo 7 de The Form of Living, en particular, desarrolla su visión del amor místico en sus diversos grados: el grado insuperable, el grado inseparable y el singular, el más elevado de todos. Recomienda reiteradamente a Margaret que se mantenga en constante oración. En el capítulo 8 explica las

22 Para una consideración de la afectividad y la devoción en la mística inglesa medieval y sus manifestaciones en Richard Rolle y otros autores, ver también el estudio de Denis Renevey. "1215-1349: texts". The Cambridge Companion to Medieval English Mysticism. Ed. Samuel Fanous y Vincent Gillespie. Cambridge: Cambridge University Press, 2011. (91-112).

23 En su ya mencionada obra, MacGinn desarrolla ampliamente los alcances de la escritura de Richard Rolle. Ver el capítulo "Richard Rolle and Sensate Affective Mysticism" (339-370).

$24 \quad$ Para un desarrollo de la devoción al nombre de Cristo en Richard Rolle y en Heinrich Seuse, ver María Eugenia Góngora, "La devoción al nombre de Cristo. Identidad y Encarnación”. Revista Stromata LXVIII. 1/2 (2012): 181-192. En ese artículo me refiero tanto a Richard Rolle como a Heinrich Seuse, el místico y predicador dominico nacido hacia 1300 y muerto en 1366. Junto al también dominico Johannes Tauler (1300-1361), fue discípulo del maestro Eckhart. 
características del grado más alto del amor; en ese estado singular, explica Richard Rolle, el alma solo piensa y desea y respira con Jesús (The Form 171). En el capítulo 9 se describe la potencia del mismo nombre y su efecto en los sentidos del oído y del gusto:

Y cuando hables con Él usando el nombre acostumbrado de Jesús, [ese nombre] será alegría en tus oídos, miel en tu boca y melodía en tu corazón ... Si piensas continuamente en el nombre de Jesús y te atas a él devotamente, te limpiará del pecado e inflamará tu corazón; iluminará tu alma, apartará sus turbulencias y eliminará su letargo; herirá tu alma con el amor y la hará sobreabundante en ese amor; alejará al demonio y eliminará el terror, abrirá el cielo y creará un/a místico/a. Mantén a Jesús en tu mente, porque él expulsará toda maldad y engaño en su amante,; y saluda a menudo a María, día y noche. Grande será el amor y la alegría si actúas de acuerdo con esta instrucción. No es necesario que desees tener muchos libros: abraza el amor en tu corazón y en tus actos y poseerás todo aquello sobre lo que podemos hablar o escribir [en los libros] ${ }^{25}(173)$

En el contexto específico de su lectura y reescritura del Cantar, y teniendo en cuenta que, después de su Form of Living, Rolle escribió un Comentario a los primeros versículos de este texto (Astell 112), me interesa aludir aquí a otra de sus obras más influyentes, el Incendium Amoris, del cual se conservan 28 manuscritos y que fue probablemente compuesto en la misma época que el Comentario. También en esta obra, así como en su Melos Amoris y Ego Dormio $^{26}$, se puede decir que el tema central es la unión amorosa con Dios y sus etapas; el título completo de su primer capítulo es indicativo en ese sentido: De conversiones hominis ad Deum, et que adyuvante et que impedium eius conversionem ${ }^{27}$. Por otra parte, como lo describe Nicholas Watson en su importante libro sobre el pensamiento y la escritura de Rolle, éste habría

25 Traducción propia.

26 En el ya mencionado estudio de Ann Astell se elaboran en detalle los usos del Cantar en estas obras de Richard Rolle, en el capítulo dedicado específicamente a sus escritos (105-118). Y de acuerdo a John Alford, el Cantar fue la obra más citada por Richard Rolle después del libro de los Salmos (cit. en Astell 107, n. 2). Esto se puede comprobar también en la "Table de citations" incluida por F. Vandenbroucke en su edición de Le Chant d'Amour. Melos Amoris. 2 vols. Paris: Cerf., 1971, vol. 2, 337-344.

27 "De la conversión del hombre a Dios, y qué ayuda y qué impide su conversión". Traducción propia. 
desarrollado paulatinamente una doctrina sobre el amor: el amor es fervor, es dulzura y es canto (fervor, dulcor, canor) ${ }^{28}$. Para Watson, el foco de una obra como Incendium Amoris estaría centrado en el fervor, así como los temas centrales de Contra Amatoris Mundi, Super Psalmum Vicesimum y Super Canticum Canticorum serían la vida contemplativa y el dulcor. Por último, el tema del canor estaría presente de manera preeminente en su Melos Amoris, una obra en la cual el canto es la forma superior de la relación amorosa con Dios, y es progresivamente más clara la identificación del místico con la Esposa del Cantar.

La identificación de la Esposa como figura femenina del alma, la integración cada vez más consciente y completa de cuerpo y alma, de los sentidos corporales y espirituales, de lo alto de lo bajo, parecen haber permitido también que Rolle dejara atrás sus primeros temores, cuando escribía de las mujeres situándolas en los polos de María o de Eva, la gran tentadora ${ }^{29}$. En su Incendium Amoris, un tratado escrito en latín y que es al mismo tiempo una autobiografía espiritual, aparece todavía en los primeros capítulos la advertencia sobre los peligros que para un ermitaño representan las mujeres; sin embargo, lo más relevante para nuestro propósito es cómo su autor se identifica como enamorado de Cristo en términos cercanos al lenguaje del Cantar, además de las abundantes citas de ese texto que están presentes junto a los Salmos, el Eclesiástico, el Eclesiastés y otros.

Del capítulo 14, que trata entre otros de en qué consiste el amor de Dios, cito estas palabras que resumen su ya mencionada síntesis del amor: "el sumo amor de Cristo consiste en tres cosas: en el fervor, en el canto y en el dulzor"( Incendium 185). En el cap. 16, leemos: “[Señor mío Jesucristo]... tú eres mi tesoro... tú eres el término del sufrimiento, la meta del trabajo, el

28 En su importante estudio, Nicholas Watson valora la elocuencia y la audacia autorial de Rolle al elaborar los aspectos del amor comofervor, dulcor y canor en sus distintas obras. Una de las dificultades planteadas por Watson en cuanto a los escritos de Rolle es la de establecer una cronología de los mismos, basándose sobre todo en la evidencia de los préstamos textuales. Para una propuesta de agrupación de los escritos tempranos, intermedios y tardíos ver "Excursus I. The Chronology of Rolle's Writing” (Watson 273-294).

29 Para una interpretación de la evolución de Rolle en relación con las figuras femeninas en general, ver Astell 112-115. Por su parte, en su estudio sobre el lenguaje de Rolle y su hermenéutica del Cantar de los Cantares, Denis Reveney releva la importancia de las mujeres en la obra de Rolle, de la importancia de la sublimación de la concupiscencia y de los peligros de la pasión carnal (68-73). 
inicio del fruto, la puerta de la alegría... por este amor languidezco, por este amor deseo morir, por este amor me enciendo" (192).

Y en el capítulo 17, luego de describir su amor por Jesús como un impulso, un ardor y un languidecer sin medida, menciona textualmente las bien conocidas palabras de la Esposa del Cantar: "Porque languidezco de amor", [quia amore langueo], (Cantar 56-8); un poco más adelante, encontramos también una glosa del Cantar en esto términos: " [En cuanto al incendio del amor divino y sus heridas] se dice: "Porque estoy herida de amor" Cantar 25 ) y "Ponme como un sello sobre tu corazón" (Cantar 8:6), y se pregunta finalmente: "¿qué es el amor sino la transformación en la cosa amada?" (194-195) Así también encontramos frecuentes referencias al Cantar en su Melos Amoris: el "beso de amor" (Cantar 1:1); la "herida de amor" (Cantar 4:9); el "languedecimiento de amor" (Cantar 2:5), y la "ebriedad del amor" (Cantar 24, y 5:1) ${ }^{30}$.

La presencia del Cantar de los Cantares en ésta y en las demás obras de Richard Rolle es sin duda muy relevante, como ya hemos mencionado, y si bien se pudo afirmar en el pasado que su autor no fue sino un principiante en la experiencia mística (Knowles 53) ${ }^{31}$, la crítica más reciente ha afirmado, en cambio, su importancia en la historia de la escritura mística y en la representación de una subjetividad medieval, tal como la desarrollan Nicholas Watson y Denis Reveney en sus estudios sobre la obra de Richard Rolle.

También es necesario considerar que en este autor y místico, un ermitaño de Yorkshire que vivió distante de las grandes órdenes tradicionales y que estuvo alejado de los centros del saber universitario, se cumple sin duda el objetivo de los grandes exégetas anteriores, es decir, el lograr que la lectura y el conocimiento directo, la experiencia del Cantar, los condujera a él y a sus lectores por un camino de encuentro con el amor divino.

En conclusión, pienso que en el caso específico de Rolle, la lectura y la reelaboración del Cantar poseen múltiples dimensiones que van más allá de las citas o del comentario exegético; entiendo también que su escritura está marcada por la fuerte afectividad de la devoción medieval tardía y por el

$30 \quad$ Bernard McGinn (345 y 614 n37) recoge algunas de estas referencias al Cantar en Melos Amoris, siguiendo la ya mencionada edición de Francois Vandenbroucke (1971) y su "Table de Citations" (vol. 2, 337-344).

31 En The English Mystical Tradition, David Knowles considera que Rolle 'falla' como místico en relación con sus propias expectativas (53); a propósito de esta valoración de Knowles, ver McGinn 340. 
carácter esponsal de la relación amorosa con Dios, propia de tantos autores que, mediante la escritura, vivieron el proceso de elaboración de este modelo de experiencia y lo transmitieron a sus lectores contemporáneos y más recientes. Una consideración sobre las características de los destinatarios medievales de los escritos de Rolle va más allá de los alcances de este ensayo, pero como Bernard McGinn afirma, es muy posible que él haya estado consciente de la amplitud de su recepción, durante los aproximadamente veinte años en los que se concentró en la composición de su obra; no solo escribió en latín y en inglés, sino que sus obras en una y en otra lengua fueron a su vez traducidas al latín o al inglés respectivamente. Es muy posible que los lectores más letrados, capaces de leer sus obras en latín, hayan experimentado la necesidad de difundirlas a un público más amplio, además de las mujeres religiosas del entorno de Rolle (McGinn 343).

La presencia del Cantar en la historia de la mística y de la subjetividad religiosa es indudable, como puede constatarse en los textos devocionales y literarios en general, tanto medievales como modernos. Sus interpretaciones concretas y su reelaboraciones suelen ser menos conocidas y, en este sentido, creo que la figura de Rolle es relevante en cuanto se trató de un hombre que se inició en un camino espiritual guiado por sus propias lecturas, por su experiencia inicial de una vida secular y luego eremítica, y que en la escritura de sus obras y gracias a la difusión que ellas tuvieron, realizó una notable síntesis de su experiencia personal y de su relación con Cristo, así como de amistad y cercanía con las mujeres religiosas de su entorno. Y en ese testimonio se manifiesta la importancia mayor de la lectura, la contemplación y la reescritura del Cantar, que se hace también presente en la gran literatura mística de siglos posteriores.

Para concluir, y volviendo al origen del Cantar de los Cantares, es relevante recordar las palabras que en la Misná y en el contexto de una discusión sobre la limpieza de las manos, se atribuyen al gran rabino Akiba, quien vivió entre la segunda mitad del siglo I DC y la primera mitad del siglo II DC: "Ningún día es tan santo como el día en el que el Cantar de los Cantares fue dado por Dios a Israel, porque todas las escrituras son santas, pero el Cantar de los Cantares es el Santo de los Santos" (Misná 1075) ${ }^{32}$.

32 La versión de la Misná editada por Carlos del Valle es: “. . . Que nadie en Israel ponga en discusión que el Cantar de los Cantares no vuelve impuras las manos, ya que el mundo entero no es digno del día en el que fue dado a Israel el Cantar de los Cantares, ya 


\section{BIBLIOGRAFÍA}

Astell, Ann W. The Song of Songs in the Middle Ages. Ithaca/London: Cornell University Press, 1990.

Bezzola, Reto. Le Sens de l'aventure et de l'amour. (Chrétien de Troyes). Paris: H. Champion, 1968.

"Cantar de los cantares". Biblia de Jerusalén. Bilbao: Desclée de Brouwer, 1975, 913-924.

“Cantar de los cantares". La Santa Biblia. Antigua versión de Casiodoro de Reina (1569) revisada por Cipriano de Valera (1602). Sociedades Bíblicas Unidas 1960. 945-950.

“Cantar de los cantares". Vulgata. A. Ed. Colunga y L. Turrado (Edición Bilingüe). Madrid: B.A.C., 1953. 819-824.

Knowles, David. English Mystical Tradition. London: Burns \& Oates, 1961.

Leclercq, Jean. The Love of Learning and the Desire of God. A study of Monastic Culture. New York: Fordham University Press, s.d.

Matter, E. Ann. The Voice of my Beloved. The Song of Songs in Western Medieval Christianity. Philadelphia: The University of Pennsylvania Press, 1990.

McGinn, Bernard. The Varieties of Vernacular Mysticism (1350-1550), Vol. V. The Presence of God, A History of Western Christian Mysticism. New York: A Herder \& Herder Book, The Crossroad Publishing Company, 2012.

Minnis, Alastair. "1215-1349: Culture and History”. The Cambridge Companion to Medieval English Mysticism. Ed. by Samuel Fanous and Vincent Gillespie. Cambridge: Cambridge University Press, 2011. 69-89.

Misná. Ed. Carlos del Valle. Biblioteca de Estudios Bíblicos 98. Salamanca: Ediciones Sígueme, 2011.

Origen. The Song of Songs. Commentary and Homilies. Trad. R. P. Lawson. New York: The Newman Press, Serie: Ancient Christian writers, no. 26, 1956.

Reveney, Denis. Language, Self \& Love. Hermeneutics in the Writings of Richard Rolle and the Commentaries on the Song of Songs. Cardiff: University of Wales Press, 2001.

Robertson, Duncan. Lectio Divina. The Medieval Experience of Reading. Collegeville, Min: Cistercian Publications Series 238, 2011.

Rolle, Richard. Incendium Amoris of Richard Rolle of Hampole. Ed. Margaret Deanesly. Manchester: University Press, 1915.

The English Writings. Ed. Rosamund S. Allen. The Classics of Western Sprituality. New York, Mahwah: Paulist Press, 1998.

San Bernardo. Sermones sobre el Cantar de los Cantares. Los Monjes Cistercienses de España. Madrid: Biblioteca de Autores Cristianos, MCMLXXXVII.

Watson, Nicholas. Richard Rolle and the Invention of Authority. Cambridge: Cambridge University Press, 1991.

que todos los hagiógrafos (Ketubim) son santos, pero el Cantar de los Cantares es santísimo" (2011: 1075). 